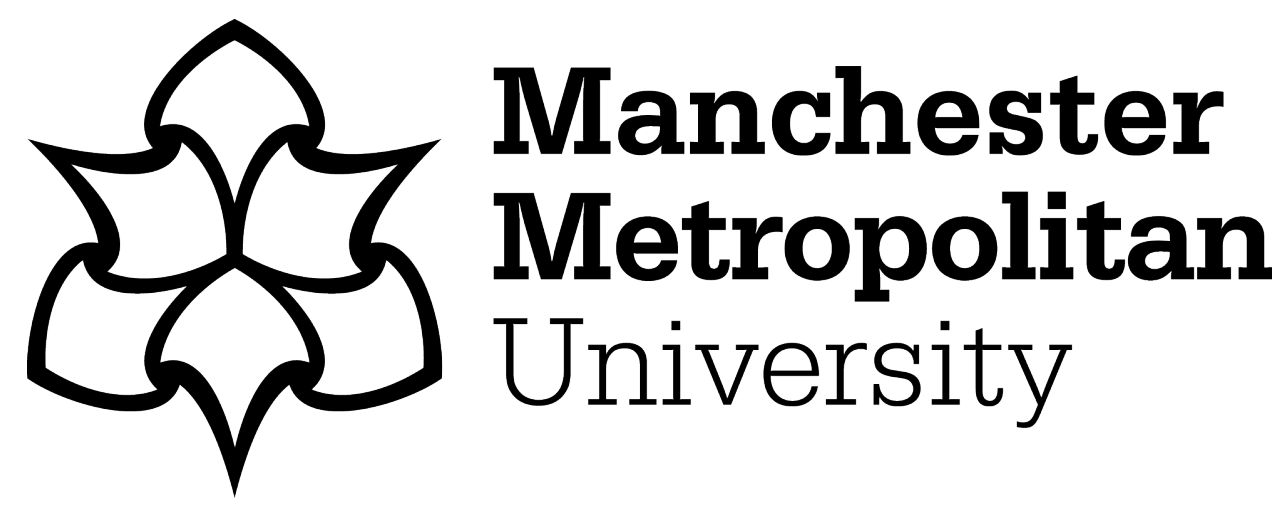

Turton, AJ, Angilley, J, Longley, V ORCID logoORCID: https://orcid.org/00000002-5492-8344, Clatworthy, P and Gilchrist, ID (2017) Search training for people with visual field loss after stroke: A cohort study. British Journal of Occupational Therapy, 81 (5). pp. 255-265. ISSN 0308-0226

Downloaded from: https://e-space.mmu.ac.uk/624201/

Version: Accepted Version

Publisher: Sage

DOI: https://doi.org/10.1177/0308022617743481

Please cite the published version 


\section{Search training for people with visual field loss after stroke: a cohort study}

Short title - Search training in occupational therapy

Ailie J Turton, Senior Lecturer, Department of Allied Health Professions, University of the West of England, Bristol

Jayne Angilley, Clinical Specialist Occupational Therapist Stroke, Stroke Therapy Team, Camborne and Redruth Community Hospital, Cornwall Partnership NHS Foundation Trust Verity Longley, PhD Student, School of Psychological Sciences, University of Manchester Philip Clatworthy, Consultant Stroke Neurologist, North Bristol NHS Trust and Stroke Association Thompson Family Senior Clinical Lecturer, University of Bristol lain D Gilchrist, Professor of Neuropsychology, School of Experimental Psychology, University of Bristol

\section{For correspondence:}

Dr Ailie Turton,

University of the West of England,

Glenside Campus, Blackberry Hill,

Bristol, BS16 1DD

(ailie.turton@uwe.ac.uk) 


\section{Abstract}

\section{Background}

People with visual field loss after stroke often experience difficulties in everyday activities. The purpose of this study was to assess the acceptability of search training as used within occupational therapy and the feasibility of possible measures for use in a future trial.

\section{Methods:}

Nine participants took part in a goal oriented intervention that was delivered three times a week for three weeks. Patient reports of acceptability and outcomes using the Visual Function Questionnaire-25 (VFQ-25) were collected. Participants' room search behaviour before and after the intervention was recorded using a head worn camera.

\section{Results:}

Eight participants completed nine treatment visits. All participants reported improved awareness and attention to the blind side during activities following the intervention. $7 / 8$ participants change scores on VFQ-25 exceeded 6 points. Patterns of head-direction behaviour and overall room search times were variable across patients; markedly improved performance was only evident in the most severely affected participant.

\section{Conclusions:}

The intervention was acceptable. The VFQ-25 is a feasible measure for assessing patient reported outcomes. While the room search was informative about individuals' behaviour, more sophisticated methods of gaze tracking would allow search processes to be determined in real world activities that are relevant to patients' goals.

Key Words: occupational therapy, stroke, hemianopia, intervention; measurement 


\section{Introduction}

An estimated $60 \%$ of stroke patients lose part of their visual field or have eye movement problems, with $35 \%$ completely losing one half of their visual field (Ali et al. 2013). These deficits often persist leading to long term limitations in activities of daily living (ADL). In one survey people with hemianopia reported poor performance in grooming, eating, mobility, reading, shopping, money management, driving, work and leisure (Warren, 2009). Hemianopia also causes people to bump into things when walking (Gilhotra et al. 2002) and increases the risk of falls (Ramrattan et al. 2001; Czernuszenko and Czlonkowska 2009).

These limitations may in part be explained by inefficient visual scanning and searching (Warren 2009). Laboratory based studies have shown that some patients with visual field deficits move their eyes to scan a display in a disorganised way. They make more repeat visits to visual targets than is normal and their eye movements towards the blind field have a reduced amplitude. Patients tend to miss some stimuli and have slower performance than controls in finding targets (Meienberg et al 1981; Zihl 1995). Patients looking at images demonstrate some intrinsic compensation for visual field loss; patients spent more time exploring the area of the picture corresponding to the blind hemifield than the seeing side (Pambakian et al. 2000). Problems are exacerbated in patients with visual field deficits who also have visuo-spatial neglect. Studies of search behaviour in patients with neglect show that they fail to explore the side of space contralateral to the cerebral hemisphere affected by the stroke and in searching they frequently revisit stimuli on the ipsilateral side (Behrmann et al. 2004). Patients with both field loss and neglect have the poorest search performance (Behrmann et al. 2004). Visual search is an integral process within many ADLs; for example, in finding items on the supermarket shelves, or avoiding hazards when walking along the pavement. If the search and scanning behaviour observed in laboratory tasks is carried over to visual function in everyday 
life, it is easy to see how occupational performance may be affected.

The consequences of visual field loss are very often long-lasting. Six months after onset, people with hemianopia may be much more limited than people with other post-stroke impairments in terms of social functioning, role limitations, and emotional well-being (Gall et al. 2010). Despite this there has been no large-scale clinical trial of rehabilitation for visual field loss after stroke. The recent UK National Clinical Guidelines for Stroke (2016) fall short of recommending or even mentioning any specific treatment. The most recent Cochrane review found only limited evidence that training compensatory visual search strategies may improve scanning and reading performance, and insufficient high quality evidence of effectiveness of treatments for improving independence in ADL (Pollock et al., 2011a). These conclusions are not significantly altered by the number of small studies that have evaluated different interventions since publication of this review (Gillen et al 2015). There is a recognised need to find better ways to help people with visual problems after stroke. The James Lind Alliance priority setting exercise for stroke rehabilitation research in Scotland has 'What are the best ways to treat visual problems after stroke?' at number five in its top ten research questions (Pollock et al 2012).

Current interventions, if offered, comprise giving information and directing patients to openly available computer based scanning and searching exercises (Rowe et al 2016; personal observations: Clatworthy http://hemianopia.blogspot.co.uk/p/for-patients.html ). While computerised training offers a cheap means for self-directed learning, it is uncertain whether learning these abstract search tasks carries over to improve performance in ADL. Visual learning effects tend to be very task specific (Schuett et al 2012); it therefore makes sense to train visual searching within occupations. Using their core skills in assessing and facilitating occupational performance, Occupational Therapists are well placed to provide task specific vision training. Visual search training is sometimes included within occupational therapy for 
people with visual problems (Pollock et al 2011b). However, opportunities to practice extended ADLs are limited in hospital, therefore occupational therapists working in community services should be more active in helping people to improve their visual performance in everyday living. A previous study of an occupational therapy intervention (table top activities), delivered in an outpatient setting, showed promise for improving participants' psychological adjustment to living with visual field loss (Taylor et al. 2011). However, this intervention was not goal oriented and it is not yet known whether visual scanning and search training in occupational therapy is effective for improving occupational performance in everyday living.

Prior to testing effectiveness of complex interventions, the UK Medical Research Council recommends defining and modelling the intervention and testing its feasibility for delivery (Craig et al. 2008). We previously described an intervention for hemianopia, based on the practice of a Specialist Community based Occupational Therapist (Turton et al. 2015). Using this description, an intervention guide was written giving the rationale for visual search training using valued activities and process activities. In the present study, we wished to determine the feasibility and acceptability of the intervention to participants when delivered three times a week for three weeks by an Occupational Therapy Technician.

Another aspect of this modelling process is to determine the mechanisms by which the intervention works, in this case how participants' search and scanning behaviour is changed as a result of the intervention. Methods for measuring patients' behaviours while searching real environments are not well developed, though this has been done in healthy subjects (Land et al 1999) and in a single case study (Land et al, 2002). Visual exploration of scenes in the real world involve not only eye but also head and whole body movements, particularly when shifting the point of gaze by more than ten degrees of visual angle (Land et al 1999; Guitton and Vole 1987; Freedman 2008). A method for measuring where the person is looking with respect to a 
scene would potentially provide information about how an intervention works. Such measurement might include the search strategies adopted, learning rates, retention and generalisation of learning to untrained tasks. Eye trackers are commonly used in laboratories or other controlled environments (Howard et al. 2011; 2013), however eye trackers are delicate and expensive. Assessing where people are looking in the wide field searches that are predominant in daily living may not require the precision of eye trackers. Because large gaze shifts involve movements of the head and trunk, a measurement of head position relative to the scene provides a proxy for gaze position. In this study we tested the suitability of using an inexpensive head worn camera to record search behaviour of participants before and after receiving the occupational therapy intervention.

A further part of the modelling process is to determine suitability of relevant outcome measures that could be used in a definitive trial. For this purpose, we selected the US National Eye Institute's Visual Function Questionnaire (VQF-25), a patient reported outcome measure comprising vision related and social constructs (Mangione et al 2001). The VFQ-25 was not developed specifically for stroke (Hepworth et al 2015), but it has good reliability and construct validity in patients with age related macular degeneration (Revicki et al 2010). We wanted to see whether the questionnaire would be able to measure change in people with visual field loss due to stroke.

In summary, our modelling phase study had three aims:

1. To test the acceptability of a three-week home based occupational therapy programme for training visual search within the context of participant's goals in everyday living tasks

2. To evaluate a room search task for its utility in determining search behaviour in the sample

3. To test the VFQ-25 as a measure of change after intervention 


\section{Method}

This was a small cohort study. Approval was obtained from South West Frenchay NHS Research Ethics Committee (ref. no. 11/SW/0306). All participants gave written informed consent. Written consent was also obtained from other adults in the household since the room search video recordings were made in their homes.

\section{Participants}

Inclusion criteria:

- $\quad$ diagnosis of stroke (physician's judgement)

- $\quad$ to be discharged to home

- $\quad$ performance in ADL affected by visual search problems (Occupational Therapist's judgement)

- failed at least one of the confrontation test (visual fields) (Pattern 1996) and Star Cancellation task from the Behavioural Inattention Test (Wilson et al.1987)

- judged as able to participate in the research processes and intervention

- $\quad$ able to consent to participation

Exclusion criteria:

- $\quad$ previous history of severe sight impairment

- $\quad$ previous history of disability affecting personal care (modified Rankin score 4 or more) (van Swieten et al. 1988)

- $\quad$ under 18 years old

- discharged to a nursing home or to residential care.

Consecutive service users fitting the eligibility criteria were identified by a community Stroke 
Care Co-ordinator and from the local hospital's stroke rehabilitation ward. Participants were recruited by Stroke Research Network Officers in the local acute stroke service or by the research Occupational Therapist in the community. Demographic characteristics of participants were collected: age, gender, side of stroke, lesion site, time since stroke, motor and sensory deficits, results of vision examination including perimetry (orthoptist's report).

Recruitment took place from 1 January 2013 to $31^{\text {st }}$ January 2014.

Intervention

The main principle of the intervention is that the search training should be specific to and tailored for the participants' goal occupations. Participants learn to systematically search all relevant areas of the environment for the task, especially to their blind side. Before commencing the intervention an assessment, goal setting and planning visit was carried out by the Research Occupational Therapist. She used her own vision assessments and goal setting procedure. Following this visit, participants received an intensive course of scanning and search training using various process activities and occupations. Task specific learning requires intensive practice and therefore it was decided that the intervention should be delivered in three one hour visits each week for three weeks. The therapy programme for this study was delivered by two part-time Occupational Therapy Technicians who were supervised by the Research Specialist Occupational Therapist. The intervention guide, written for use in the study, provided direction and examples indicating: how to educate the participant about the effects of their visual problems on ADL performance and the need for compensatory strategies; the use of systematic scanning within the context of meaningful and goal specific activities; the use of process (or remedial) activities to intensively train search strategies, for example beginning to search a table top or room on the blind side and to systematically search back towards the seeing side; 
grading difficulty by manipulating distractors and the area of space for the task (Turton et al 2015). One or two ADLs were selected for practice according to the participant's goals. Examples include preparing food or drinks, playing a card game, or steering a powered wheelchair, or outdoor tasks such as walking in the street or shopping. To demonstrate fidelity to the intervention the Occupational Therapy Technicians completed structured treatment logs giving details of activities used, their purpose and examples of search strategies and comments on participants' performance.

Participants were encouraged to record their experiences of occupational therapy visits, to act as a reminder when asked to answer a structured questionnaire about their perceptions of the intervention. This questionnaire was completed either by telephone, or face to face if time allowed. It comprised closed questions about the acceptability of the frequency of visits, and whether the benefits justified the effort required to participate. Participants were asked to rate how beneficial they perceived the intervention to be on an 11-point numerical scale ( 0 being not at all beneficial, 10 being extremely beneficial). They were also asked what difference they thought the intervention had made to them and what they liked and disliked about it. While it is acknowledged that having the therapy team ask the questions risked biasing participants' responses, the advantage was that the team would gain a more detailed understanding of how the intervention might be improved.

Room search process measurement

[figure 1 near here]

The room search task was developed by the research team for this study. A small, familiar, unobtrusive object belonging to the participant was searched for, for example a key on a fob. The task was standardised as much as possible within the participant's home setting. A Go-Pro 
digital video camera was positioned squarely on the participant's head and secured with an elastic strap (figure 1 inset). The position of the camera was aligned using a laser pointer to ensure the camera was facing straight ahead. The participant was seated centrally against one wall of the room; giving scope for searching the room directly in front of them and to their extreme left and right sides. The tester divided the room mentally into eight sections from the point of view of the participant; no physical markers were used. The facing wall and area in front of the participant was divided into central left upper and lower quadrants and each peripheral wall or space was divided into upper and lower halves (see figure 1). Sixteen searches were performed with the object being placed twice in each of the eight sections. The order in which locations were used across trials was random.

The participant was seated with eyes closed while the object was very quietly placed to minimise auditory cues. The participant was told when to open eyes to start each search. Each search was recorded from the head camera and timed manually using a stopwatch. Searches were stopped after 120 seconds if the object had not been found, to prevent frustration, demoralisation or boredom. The room search task was piloted on a sample of ten healthy volunteers who searched symmetrically across the rooms used (Turton, 2014, pp15-17).

The room search task was carried out at the first assessment visit and in the week after completion of the intervention. The task was administered by the Research Occupational Therapist, with the help of an Occupational Therapy Technician. Resources did not allow for an independent assessor.

VFQ25

The VFQ-25 was administered on the assessment visits before and after the intervention by the Research Occupational Therapist. The VFQ-25 represents 11 vision related constructs: general 
vision, ocular pain, near vision, distance vision, driving, peripheral vision, colour vision, role limitations, dependency, social function, and mental health, plus a general health question. Rasch analysis has suggested that the measure may have better internal consistency without the items for general health, pain around the eyes, and driving, and that its constructs could be collapsed into visual functioning and socio-emotional scales, respectively (Marella et al 2010). The minimal important difference of the total composite VFQ-25 score was 6.13 points in a study of patients with diabetic macular oedema (Lloyd et al. 2013).

\section{Data Analysis}

To indicate feasibility, the number of intervention visits was counted and the tasks and activities summarised and compared with the intended number and scope of the visits. For assessment of acceptability, responses to the participants' questionnaire about the intervention were collated.

Video recordings of the room search task were independently coded by a university researcher. Sports analysis video player software (Kinovea), was used to create cross hairs which were aligned to the centre of point of view of the camera and therefore the direction that the head was pointing. With reference to a diagram showing the room divisions (as in figure 1), the video was played slowly so that the assessor could follow the cross hairs as it played and record the head-direction sequence on the diagram. A new head direction was coded when the camera crossed into a new segment, for example "upper left, upper central left, upper central right", etc. 'Head direction' refers to the position in space to which the centre of the head is pointing; in natural viewing this approximates the region in space to which the eyes and so the centre of the visual field is directed. The number of head-directions in each section of the room was calculated for each trial and summed across all 16 trials. From this a proportion of head- 
directions in each half of the room was calculated. In addition, the first five head-directions for each trial were used to count the early search head-directions on each side of the room (blind or seeing side). For these frequencies, we calculated $95 \%$ confidence intervals for each patient. The durations of trials were summarised as medians with interquartile ranges. A note was made of the trials truncated at 120 seconds and the position of the object in these failed searches.

In presenting the data we have taken a case series approach to preserve the diversity of the participant sample.

VFQ-25 scoring was carried out in accordance with the test manual: raw scores were recoded to percentages of the maximum scores and items within each subscale averaged together to create subscale scores; the average of the sub-scale scores provided an overall composite score. Change scores for each subsection were determined. As suggested by Marella et al (2010) items general health, pain around the eyes, and driving were excluded from the analysis.

\section{Results}

Fourteen participants were recruited to the study. However, five withdrew before participation: two having completely recovered; one was too ill, one was discharged into care and one no longer wanted to participate. Of the nine participants remaining five were male; ages ranged from 54 to 84 ; seven had hemianopia, the remaining two had partial visual field loss on one side; eight had left-sided visual loss; four had coexisting visual inattention. Participants' characteristics are given in table 1. The goals and activities used are given in table 2. Activities were chosen according to participants' goals. Six participants had goals that related to mobility (on foot or in a wheelchair), either inside or outside the home; four wanted to return to driving; two participants wanted to return to work; six had goals related to meal preparation; three wanted to improve their ability to work on a computer and three wanted to improve their reading. 
Since driving was not possible the goal to return to driving was addressed by focussing on improving awareness and scanning to the affected side over distances similar to those used when driving, when out walking or sitting in a stationary car.

[tables $1 \& 2$ near here]

Process training activities such as finding playing cards from an array on a table top or across the floor were used with all participants to increase insight into the effects of visual field loss and to provide intensive practice in using new search strategies before trying them out in goal tasks. Eight participants had all nine intervention visits; participant $E$ received eight visits, after which he returned to work.

Participants' views of the intervention

Eight participants completed the questionnaire giving their views of the intervention and perceived benefits (Table 3). All respondents found the number of visits and the treatment acceptable and thought the intervention worth the effort required.

[Table 3 near here]

[Figure 2 near here]

Room search results

Figure $2 \mathrm{~A}$ shows the percentage of head-directions in the half of the room on participants' blind side before and after intervention. All nine participants directed their head movements to both sides of the room. Figure $2 \mathrm{~A}$ shows evidence of an increase in searching in the blind side following the intervention for participants C, F and G. Participant A appeared to search the blind field less following the intervention. Note that this participant demonstrated a strong bias 
towards searching the blind field rather than the good field before the intervention; given that the target is equally likely to be in either side of the room this change could be considered adaptive.

Figure $2 \mathrm{~B}$ shows the same data as Figure $2 \mathrm{~A}$ but for the first five head-directions only.

Participant $\mathrm{A}$ again displays a strong bias to start the search on the blind side both before and after training. Participant G's increase in searching the blind field after treatment is evident in this early search phase. Participants $\mathrm{H}$ and I show a dramatic decrease in early search of the blind side after treatment, but comparison with Figure 2A suggests this must be compensated for by searching the blind side later in the search process.

Figures $2 \mathrm{C}$ and 2D plot participants' median search times and interquartile range (IQR). There is little data available here per participant so only qualitative comparisons are appropriate. Search times were very variable overall with a number of trials being stopped at the 120 second limit. Except for participant $F$, there is no clear link visible between head-direction behaviour and overall search times across patients.

\section{VFQ-25}

Table 4 shows participants' composite scores before and after training with changes in composite and domain scores. Positive values represent improved scores. Participants' assessments of their visual functioning ranged widely; composite percentage scores ranged from 20.3 to 83.6 before training. Participants A, B and G reported mild limitations; others reported more severe deficits and socio-emotional impact. Composite scores for all eight participants who completed the VFQ-25 after treatment were improved; in all of them except G this exceeded the estimated minimally important difference of 6.3. Gains after treatment were seen across domains.

[Table 4 near here] 


\section{Discussion}

Goal specific visual search training was delivered to nine participants with stroke affecting visual functioning. This small sample contained a wide range of visual and physical functioning. Consequently, we applied visual search training to a diverse range of everyday activities.

The intervention utilised activities identified as goals by the participants and was delivered intensively in one hour visits, three times a week for three weeks by Occupational Therapy Technicians. This is more intensive than is usual in the local community occupational therapy service where the Research Occupational Therapist works, where visits to service users with visual problems after stroke are typically once a fortnight or once a month over several months. After three weeks of more intensive intervention the study participants reported increased awareness of their visual field loss, being better able to find things and carry out everyday activities. They found the frequency of visits acceptable and considered the benefits to be worth the work done. Occupational therapy is a complex intervention and may have differing effects and influences on different individuals. While the amount of training given was deemed acceptable by participants and intensity of practice is important for learning, the duration of the therapy programme could be varied according to individual need.

Accurate and sensitive methods for measuring visual search performance in everyday activities are needed to determine learning achieved. The room search task was designed to capture search behaviour in a familiar space. In training compensatory search strategies, we aim for more efficient and successful searching. The room search results showed that search behaviour varies between individuals. In concurrence with previous findings of intrinsic compensation in viewing images (Pambakian et al., 2000), our room search results showed that some individuals had already begun to spend more time searching on their blind side before the start of the 
intervention. Nevertheless, searching on the blind side was increased after the intervention in some patients, though this did not necessarily decrease search duration. While overall the room search results demonstrated considerable variation across participants, one participant stood out as having substantially improved success in searching; participant $F$ showed remarkable improvements in the time taken to find objects to her blind side after treatment. This participant was the most impaired in terms of inattention and eye movements; she was unable to direct her gaze to the left and was severely physically impaired. Four months post stroke she was dependent in personal care and transfers and could not move around her home. The goal directed intervention included searching for clothes in her wardrobe, kitchen activities and driving an electric wheelchair. Although we cannot be certain her improved performance was not due to spontaneous recovery (Farne et al. 2004), it is likely to have been influenced by the opportunity the intervention provided to intensively learn to explore her environment.

The room search task proved to be useful in investigating search behaviour in a real world space and was low cost and robust. This is an important departure from tests used in clinical practice where performance is usually confined to narrow field tasks in near space using computer screens or pencil and paper cancellation tasks (Pollock et al 2011a). We believe the room search task represents a significant and important improvement on current process measures. However, it still suffers from a number of limitations: It was a stationary task and was very deliberately used to test performance, without the distractions of real ADLs. Consequently, participants' performance may not reflect their behaviour in real life. This static task may not be very informative about activities in which the participant is moving about, for example walking around outside or in shops, driving a wheelchair or in kitchen activities.

Different real world tasks have different speed and accuracy requirements and perhaps different search strategies should be encouraged accordingly. The intervention was substantially goal 
directed and performance measures should be relevant to the tasks that the intervention is aiming to influence. Camera technology is improving: in the short space of time since we started this study affordable spectacles with digital video cameras set into the bridge have become readily available. More sophisticated software for mapping gaze to the environment are also developing (Leelasawassuk, et al. 2015; Lukierski, et al. 2017). Currently the technology cannot reliably capture where the viewer is looking in busy environments or poorly lit conditions, but once these challenges are met, understanding search patterns in everyday life may be more accessible and become part of process measurement in occupational therapy practice.

The VFQ-25 measured change after the intervention across participants. Change scores indicated probable clinically important improvements, suggesting greater confidence in everyday living and participation. Of course, these perceived gains may not have been due to the intervention; there was no control group nor methods to reduce bias. Natural recovery, increased attention from the research therapy team, the familiarity and possible bias of the administrator, or other influences may have affected the change in VFQ-25 scores. However, the results suggest the VFQ-25 could be a useful outcome measure in a larger randomised control trial.

In conclusion, this study has established that this visual search training programme tested is feasible and acceptable within community based occupational therapy and was generally liked by participants. The VFQ-25 appears to be a good candidate for an outcome measure in a future clinical trial. We have taken a step forwards towards evaluating the intervention and determining an appropriate outcome measure for a future trial.

\section{Key findings}

- A community based occupational therapy intervention to train visual search in people 
affected by stroke is acceptable and feasible.

- A room search task was informative about individuals' performance, but more sophisticated methods are needed to evaluate search processes in a variety of real world activities.

\section{What the study has added}

The study has shown that this intervention is acceptable and feasible. It has also demonstrated measurement of search in the home context.

\section{Acknowledgements}

Laura Paterson and Sue Reynolds, Peninsula Community Health Occupational Therapy

Service, delivered the intervention, with supervision from Jayne Angilley. We are grateful to the Therapy Services manager, Gill Mead, for her support for this project. Thanks to Dr Iris Terrer Dimwadyo for providing independent analysis of the room search videos. Last but not least, our warmest thanks to the participants.

\section{Ethics approval}

Approval for the studies was obtained from South West Frenchay NHS Research Ethics Committee (ref. no. 11/SW/0306, Occupational Therapy Vision After Stroke 28/10/2011)

\section{Declaration of conflicting interests}

The Authors confirm that there is no conflict of interest

\section{Funding}

This study was funded by a Research Priority Grant from the UK Occupational Therapy Research Foundation. 


\section{References}

Ali M, Hazelton C, Lyden P, et al. (2013) Recovery from poststroke visual impairment: Evidence from a clinical trials resource. Neurorehabilitation and Neural Repair 27(2): 133-141.

Behrmann M, Ebert P and Black SE (2004) Hemispatial neglect and visual search: a large scale analysis. Cortex 40, 247-263

Craig P, Dieppe P, Macintyre S, et al. (2008) Developing and evaluating complex interventions: the new Medical Research Council guidance. British Medical Journal 337: 979-983.

Czernuszenko A and Czlonkowska A (2009) Risk factors for falls in stroke patients during inpatient rehabilitation. Clinical Rehabilitation 23: 176-188.

Farnè A, Buxbaum LJ, Ferraro M, et al (2004), Patterns of spontaneous recovery of neglect and associated disorders in acute right brain-damaged patients Journal of Neurology, Neurosurgery \& Psychiatry 75:1401-1410.

Freedman EG (2008) Coordination of the eyes and head during orienting. Experimental Brain Research 190: 369-387.

Gall C, Franke GH and Sabel BA (2010) Vision-related quality of life in first stroke patients with homonymous visual field defects. Health and Quality of Life Outcomes 8: 33. Published online 2010 Mar 26. doi: 10.1186/1477-7525-8-33

Gilhotra JS, Mitchell P, Healey PR, et al. (2002) Homonymous visual field defects and stroke in an older population. Stroke 33: 2417-2420.

Gillen G, Nilsen DM, Attridge J, et al. (2014) Effectiveness of interventions to improve 
occupational performance of people with cognitive impairments after stroke: An evidence-based review. American Journal of Occupational Therapy 69 Published online: 6901180040p16901180040p9. doi:10.5014/ajot.2015.012138

Guitton D and Volle M (1987) Gaze Control in Humans - Eye-head coordination during orienting movements to targets within and beyond the oculomotor range. Journal of Neurophysiology 58 , 427-459.

Hepworth LR, Rowe FJ, Harper R, et al. (2015) Patient reported outcome measures for visual impairment after stroke: a systematic review. Health and Quality of Life Outcomes 13:146 Published online 2015 Sep 15. doi: 10.1186/s12955-015-0338-x

Howard CJ, Pharaon RG, Körner C, et al. (2011) Visual search in the real world: Evidence for the formation of distractor representations. Perception 40, 1143-1153.

Howard CJ, Troscianko T, Gilchrist ID, et al. (2013) Suspiciousness perception in dynamic scenes: a comparison of CCTV operators and novices. Frontiers in Human Neuroscience 7, 441. Published online 2013 Aug 22. doi: 10.3389/fnhum.2013.00441

Land MF, Mennie N and Rusted J (1999) The roles of vision and eye movements in the control of activities of daily living. Perception 28: 1311-1328

Land MF, Furneaux, SM and Gilchrist ID. (2002). The organisation of visually mediated actions in a subject without eye movements Neurocase 8, 80-87.

Leelasawassuk T, Damen D and Mayol-Cuevas WW (2015). Estimating Visual Attention from a Head Mounted IMU. In: ISWC '15 Proceedings of the 2015 ACM International Symposium on Wearable Computers. Osaka, Japan — September 07 - 11, 2015 ISBN 978-1-4503-3578-2, pp. 147-150. Association for Computing Machinery New York USA 
Lloyd AJ, Loftus J, Turner M, et al. (2013) Psychometric validation of the Visual Function Questionnaire-25 in patients with diabetic macular edema. Health and Quality of Life Outcomes 11:10. Published online 2013 Jan 24. doi: 10.1186/1477-7525-11-10

Lukierski R, Leutenegger S and Davidson AJ (2017) Room layout estimation from rapid omnidirectional exploration. IEEE International Conference on Robotics and Automation (ICRA) Singapore 29 May-3 June 2017 IEEE Xplore Digital Library. Available at: http://ieeexplore.ieee.org/abstract/document/7989747/?part=1 (accessed 29 Aug 2017)] Mangione CM, Lee PP, Gutierrez PR, et al. (2001) Development of the 25-item National Eye Institute Visual Function Questionnaire (VFQ-25), Archives of Ophthalmology 119, 1050-1058 Meienberg O, Zangemeister WH, Rosenberg M, et al. (1981) Saccadic eye movement strategies in patients with homonymous hemianopia. Annals of Neurology 9:537-44.

Marella M, Pesudovs K, Keeffe JE, et al. (2010) The Psychometric Validity of the NEI VFQ-25 for Use in a Low-Vision Population. Investigative Ophthalmology \& Visual Science 51, 28782884

National Clinical Guidelines for Stroke (2016) Available at https://www.rcplondon.ac.uk/guidelines-policy/stroke-guidelines (accessed 23 January 2017) Pambakian ALM, Wooding DS, Patel N, et al. (2000) Scanning the visual world: a study of patients with homonymous hemianopia Journal of Neurology Neurosurgery and Psychiatry 69: 751-759

Pattern J (1996) Neurological differential diagnosis, Heidelberg: Springer-Verlag, pp18.

Pollock A, Hazelton C, Henderson CA, et al. (2011a) Interventions for visual field defects in 
patients with stroke. Cochrane Database of Systematic Reviews 2011, Issue 10. Art. No.: CD008388.

Pollock A, Hazelton C, Brady M (2011b) Visual Problems After Stroke: A survey of current practice by Occupational Therapists working in UK stroke inpatient settings. Topics in Stroke Rehabilitation 18 (Suppl 1): 643-653

Pollock A, St George B, Fenton M, et al. (2012) Top ten research priorities relating to life after stroke. Lancet Neurology, 11 (3) 209 [also at James Lind Alliance, Stroke in Scotland Priority Setting Partnership http://www.jla.nihr.ac.uk/priority-setting-partnerships/stroke-in-scotland/top10-priorities/ (accessed 23 January 2017)

Ramrattan RS, Wolfs RC, Panda-Jonas S, et al. (2001) Prevalence and causes of visual field loss in the elderly and associations with impairment in daily functioning: The Rotterdam Study. Archives of Ophthalmology 119: 1788-94

Revicki DA, Rentz AM, Harnam N, et al. (2010) Reliability and validity of the National Eye Institute Visual Function Questionnaire-25 in patients with age-related macular degeneration. Investigative Ophthalmology and Visual Science 51(2):712-7.

Rowe F, Walker M, Rockliffe J, et al. (2016) Delivery of high quality stroke and vision care: experiences of UK services. Disability and Rehabilitation 38 (8): 813-817

Schuett S, Heywood CA, Kentridge RW, et al. (2012) Rehabilitation of reading and visual exploration in visual field disorders: transfer or specificity? Brain,135(3): 912-21.

Taylor L, Poland F, Harrison P, et al. (2011) A quasi-experimental feasibility study to determine the effect of a systematic treatment programme on the scores of the Nottingham Adjustment Scale of individuals with visual field deficits following stroke. Clinical Rehabilitation 25: 43-50. 
Turton A (2014) Description and measurement of visual scanning training in Occupational Therapy for patients with visual search deficits following stroke. Final Project Report College of Occupational Therapists and the University of the West of England. Available at http://eprints.uwe.ac.uk/30808/ (accessed 27 Jan 2017)

Turton AJ, Angilley J, Chapman M, et al., (2015) Visual search training in Occupational Therapy - an example of expert practice in community based stroke rehabilitation, British Journal of Occupational Therapy 78: 674-687

van Swieten JC, Koudstaal PJ, Visser MC, et al. (1988) Interobserver Agreement for the Assessment of Handicap in Stroke Patients. Stroke 19: 604-607.

Warren M (2009) Pilot study on activities of daily living limitations in adults with hemianopsia. American Journal of Occupational Therapy 63: 626-633.

Wilson B, Cockburn J and Halligan P (1987) Development of a behavioural test of visuospatial neglect. Archives of Physical Medicine and Rehabilitation 68: 98-102.

Zihl J. (1995) Visual scanning behaviour in patients with homonymous hemianopia. Neuropsychologia 33: 287-303. 
Table 1. Participants

\begin{tabular}{|c|c|c|c|}
\hline $\begin{array}{l}\text { ID. } \\
\text { Gender } \\
\text { Age }\end{array}$ & $\begin{array}{l}\text { Stroke lesion } \\
\text { site }\end{array}$ & $\begin{array}{l}\text { Months } \\
\text { post } \\
\text { stroke }\end{array}$ & Vision assessment: impairment and reported impact \\
\hline $\begin{array}{l}\text { A } \\
\text { Male } \\
64\end{array}$ & $\begin{array}{l}\text { left temporo- } \\
\text { occipital } \\
\text { infarct }\end{array}$ & 7 & $\begin{array}{l}\text { Right homonymous hemianopia, good corrected acuity for near } \\
\text { and distance vision. Diabetes type II; 54/54 on star cancellation } \\
\text { test. No evident ocular motor deficits. No restriction of neck } \\
\text { movement. Reported difficulty reading and using computer; not } \\
\text { driving due to visual impairment }\end{array}$ \\
\hline $\begin{array}{l}\text { B } \\
\text { male } \\
58\end{array}$ & $\begin{array}{l}\text { right middle } \\
\text { cerebral } \\
\text { artery infarct }\end{array}$ & 2 & $\begin{array}{l}\text { Left inferior quadrantanopia, good corrected acuity for near and } \\
\text { distance. } 54 / 54 \text { on star cancellation test. No evident ocular } \\
\text { motor deficits, but finds it more difficult to switch his gaze to the } \\
\text { left. No restriction of neck movement. Reports visual problems } \\
\text { as "a problem with his left side, which is intermittent, sporadic } \\
\text { and pertinent when he is not paying attention". He reports that } \\
\text { he can be "impulsive and not good at acknowledging items on } \\
\text { his left side". Bumps into things on left when walking outside. } \\
\text { Not driving because of his visual deficit. Research Occupational } \\
\text { Therapist considered visual inattention in extra-personal space } \\
\text { probable }\end{array}$ \\
\hline $\begin{array}{l}\mathrm{C} \\
\text { male } \\
65\end{array}$ & $\begin{array}{l}\text { right middle } \\
\text { cerebral } \\
\text { artery infarct }\end{array}$ & 6 & $\begin{array}{l}\text { Left homonymous hemianopia, good corrected acuity for near } \\
\text { and distance vision. No errors on star cancellation test. No } \\
\text { evident ocular motor deficits. Range of neck movement is full for } \\
\text { flexion and rotation, but reduced in extension. Reported that he } \\
\text { "cannot see detail, it's like a sheet of polythene is hanging down } \\
\text { on the left-hand side. If I look straight ahead I cannot see on the } \\
\text { left". }\end{array}$ \\
\hline $\begin{array}{l}D \\
\text { female } \\
73\end{array}$ & $\begin{array}{l}\text { small } \\
\text { haemorrhage } \\
\text { posterior to } \\
\text { the right } \\
\text { internal } \\
\text { capsule. }\end{array}$ & 2 & $\begin{array}{l}\text { Left homonymous hemianopia plus loss of peripheral vision to } \\
\text { the right on perimetry. Good corrected acuity for near and } \\
\text { distance vision. Some scarring in right eye following an infection. } \\
\text { Errors to the left and right on star cancellation test ( } 37 / 54) \\
\text { Difficulty with ocular pursuit, particularly when attempting to } \\
\text { track to the left. Full range of rotational neck movements, but } \\
\text { flexion and extension restricted by pain. Perceived visual } \\
\text { problems: described as "seeing things but difficulty registering } \\
\text { that I have seen them". And not seeing clearly on the left side. } \\
\text { Some difficulty with face recognition. }\end{array}$ \\
\hline $\begin{array}{l}\mathrm{E} \\
\text { male } \\
54\end{array}$ & $\begin{array}{l}\text { right sided } \\
\text { occipital } \\
\text { infarction }\end{array}$ & 3 & $\begin{array}{l}\text { Left homonymous hemianopia, good corrected acuity for near } \\
\text { and distance vision. 54/54 on star cancellation test. Reports lack } \\
\text { of confidence in walking outside. Unable to drive is his main } \\
\text { concern as it affects ability to work. Vision worse first thing in } \\
\text { morning. Gets tired, takes longer than it used to do activities. }\end{array}$ \\
\hline
\end{tabular}




\begin{tabular}{|c|c|c|c|}
\hline $\begin{array}{l}\text { F } \\
\text { Female } \\
84\end{array}$ & $\begin{array}{l}\text { Right middle } \\
\text { cerebral } \\
\text { artery infarct }\end{array}$ & 4 & $\begin{array}{l}\text { Left sided homonymous hemianopia, and visual neglect. Only } \\
\text { cancelling far right column of stars on star cancellation test. } \\
\text { Good corrected acuity for near and distance vision, impaired eye } \\
\text { movements, unable to direct gaze to left. Pre-stroke history of } \\
\text { glaucoma; Unable to read; } 2 / 3 \text { range of neck rotation, left and } \\
\text { right. Dependent in personal care, household tasks, transfers } \\
\text { and meals and in moving around. }\end{array}$ \\
\hline $\begin{array}{l}\text { G } \\
\text { Female } \\
75\end{array}$ & $\begin{array}{l}\text { Right } \\
\text { cerebral } \\
\text { haemorrhage }\end{array}$ & 30 & $\begin{array}{l}\text { Left hemianopia, good corrected acuity for near and distance } \\
\text { vision, possibly some left sided inattention - Achieved cut off } \\
\text { score 51/54 (missing } 3 \text { stars to the left) on star cancellation. No } \\
\text { evident ocular motor deficits. Restricted to } 2 / 3 \text { of neck rotation, } \\
\text { left and right. Dependent in personal care, household tasks, } \\
\text { transfers and meals and in moving around. }\end{array}$ \\
\hline $\begin{array}{l}\mathrm{H} \\
\text { Female } \\
66\end{array}$ & $\begin{array}{l}\text { Right } \\
\text { cerebral } \\
\text { haemorrhage }\end{array}$ & 36 & $\begin{array}{l}\text { Left hemianopia and inattention to left; } 50 / 54 \text { (missed } 4 \text { stars to } \\
\text { the right) on star cancellation. Good corrected acuity for near } \\
\text { and distance vision. Astigmatism in left eye since childhood. } \\
\text { Limited range of movement in her neck, particularly in } \\
\text { extension, and rotation to the left. Complains she does not see } \\
\text { well on both sides, she bumps into things and would not be able } \\
\text { to cross roads. }\end{array}$ \\
\hline $\begin{array}{l}\text { Male } \\
83\end{array}$ & $\begin{array}{l}\text { Right } \\
\text { Occipital } \\
\text { lobe, } \\
\text { Posterior } \\
\text { circulation } \\
\text { infarct }\end{array}$ & 2 & $\begin{array}{l}\text { Partial visual field loss on the left, with macular involvement. } \\
\text { Achieved cut off score } 51 / 54 \text { (missing } 3 \text { stars to the left) on star } \\
\text { cancellation. Difficulties with reading. Visual deficit impacts on } \\
\text { kitchen tasks, and moving around the home, tends to bump into } \\
\text { things. Complains he cannot see as he used to: can't read, use } \\
\text { the computer or attend to his financial affairs and is unable to } \\
\text { drive. }\end{array}$ \\
\hline
\end{tabular}


Table 2. Goals and activities

\begin{tabular}{|c|c|c|}
\hline Participant & Goals & Activities used in intervention \\
\hline A & $\begin{array}{l}\text { To improve reading } \\
\text { ability and speed. } \\
\text { To improve use of } \\
\text { computer. } \\
\text { To drive on public roads. }\end{array}$ & $\begin{array}{l}\text { Reading written instructions, Computer game of Mahjong } \\
\text { Finding tools in shed. } \\
\text { Remedial activities to improve amplitude of eye } \\
\text { movements } \\
\text { Search training - spelling out words from letters on post-it } \\
\text { notes on wall. Sorting words across table. }\end{array}$ \\
\hline B & $\begin{array}{l}\text { To return to work } \\
\text { To drive (essential for } \\
\text { work) } \\
\text { To walk outside } \\
\text { independently } \\
\text { To use computer for } \\
\text { work-based tasks }\end{array}$ & $\begin{array}{l}\text { Outdoor mobility, walking, crossing roads and riding } \\
\text { bicycle on side road. } \\
\text { Computer game 'Dr Monocle's Mansion' visual scanning. } \\
\text { Working on case study on the computer } \\
\text { Remedial activities: card search on table; searching for } \\
\text { items around house: Catch and throw game to increase } \\
\text { speed of orientation to the left; Searching for laser pointer } \\
\text { dot at speed. } \\
\text { Spelling words on from letters on post-it notes placed over } \\
\text { the wall. }\end{array}$ \\
\hline C & $\begin{array}{l}\text { To be able to drive again. } \\
\text { To be able to go out and } \\
\text { about in community with } \\
\text { confidence. } \\
\text { To be able to prepare } \\
\text { food at home. }\end{array}$ & $\begin{array}{l}\text { Walking outside; Shopping in familiar supermarket and in } \\
\text { unfamiliar supermarket; Searching for items in kitchen and } \\
\text { garage. } \\
\text { Searching of post-it notes on tree trunks outside. } \\
\text { Visit to park and searching for wildlife. } \\
\text { Remedial activities: card games such as solitaire, matching } \\
\text { games }\end{array}$ \\
\hline D & $\begin{array}{l}\text { To be able to vacuum the } \\
\text { carpet in the house. } \\
\text { To walk around outside } \\
\text { with confidence, } \\
\text { including fetching } \\
\text { grandchildren from } \\
\text { school } \\
\text { To be able to get her own } \\
\text { meals. }\end{array}$ & $\begin{array}{l}\text { Kitchen tasks incorporating visual searching: organising } \\
\text { freezer, making a cup of tea with items moved to different } \\
\text { places than usual } \\
\text { Outdoor mobility was the main focus of treatment. } \\
\text { Walking outside and crossing road. } \\
\text { Remedial activities to train systematic search starting from } \\
\text { the affected side: Searching for pegs with high contrast } \\
\text { tape and without. Searching for features in pictures. Card } \\
\text { search. }\end{array}$ \\
\hline $\mathbf{E}$ & $\begin{array}{l}\text { To return to work as a } \\
\text { chef in busy kitchens, } \\
\text { being confident and quick } \\
\text { when using knives. } \\
\text { Driving }\end{array}$ & $\begin{array}{l}\text { Cooking, preparing more complex meals as the treatment } \\
\text { progressed and to simulate restaurant tasks these were } \\
\text { timed. } \\
\text { Mobility outdoors: walking and negotiating roads whilst } \\
\text { talking. } \\
\text { Visit to job centre with the therapist to discuss options for } \\
\text { access to work. } \\
\text { Remedial activities to promote his insight into his visual } \\
\text { deficit. }\end{array}$ \\
\hline
\end{tabular}




\begin{tabular}{|c|c|c|}
\hline $\mathbf{F}$ & $\begin{array}{l}\text { To read the newspaper, } \\
\text { do crossword puzzles, } \\
\text { word search } \\
\text { To be able to go out to } \\
\text { look at the shops } \\
\text { To be able to use a } \\
\text { powered wheelchair }\end{array}$ & $\begin{array}{l}\text { Selecting clothes in wardrobe, kitchen search for tins, } \\
\text { pouring water from jug to mug, preparation of ingredients } \\
\text { for baking buns } \\
\text { Wheelchair driving indoors } \\
\text { Washing and dressing including finding objects and } \\
\text { clothing needed } \\
\text { Hoovering and dusting } \\
\text { Remedial activities- Letter search on post it notes table top }\end{array}$ \\
\hline G & $\begin{array}{l}\text { To be able to use a } \\
\text { powered wheelchair in } \\
\text { the home environment. } \\
\text { To be able to put the } \\
\text { washing in the washing } \\
\text { machine. } \\
\text { To make a snack for } \\
\text { herself. } \\
\text { Gardening. }\end{array}$ & $\begin{array}{l}\text { visual search with kitchen items } \\
\text { making bed } \\
\text { loading washing machine using long handled reacher } \\
\text { making sandwich } \\
\text { reading from magazine } \\
\text { mobility in powered wheelchair } \\
\text { Remedial activities - table top card game; picture } \\
\text { matching over wide field on floor; throwing and catching a } \\
\text { ball }\end{array}$ \\
\hline H & $\begin{array}{l}\text { To be able to attend to } \\
\text { people on the left side. } \\
\text { To attend to objects on } \\
\text { the left side when eating. } \\
\text { To be able to move safely } \\
\text { around the house } \\
\text { without bumping into } \\
\text { things. } \\
\text { To be able to prepare } \\
\text { vegetables. } \\
\text { To be able to iron. }\end{array}$ & $\begin{array}{l}\text { preparing a sandwich } \\
\text { silk painting craft } \\
\text { dressing } \\
\text { ironing } \\
\text { games on ipad } \\
\text { kitchen tasks, cleaning cutlery drawer, cleaning grill } \\
\text { machine } \\
\text { Remedial activities- playing cards and post it note word } \\
\text { search }\end{array}$ \\
\hline $\mathbf{I}$ & $\begin{array}{l}\text { To be able to drive } \\
\text { To be able to read and } \\
\text { use the computer } \\
\text { To be more aware of the } \\
\text { layout of the kitchen } \\
\text { environment }\end{array}$ & $\begin{array}{l}\text { keyboard search } \\
\text { room searches: kitchen, office, garage } \\
\text { making hot drink } \\
\text { sorting filing system } \\
\text { outdoor mobility and locating things in environment and } \\
\text { shops } \\
\text { Remedial activities- narrow field table top post it notes and } \\
\text { card searches; ball throwing and catching }\end{array}$ \\
\hline
\end{tabular}


Table 3. Participants' observations of the benefit of the intervention

\begin{tabular}{|c|c|c|}
\hline Participant & $\begin{array}{l}\text { Responses to the questions - What difference has the treatment made to } \\
\text { you? } \\
\text { What did you like about the Occupational Therapy; What did you not like? }\end{array}$ & $\begin{array}{l}\text { Benefit } \\
\text { rating / } \\
10\end{array}$ \\
\hline A & $\begin{array}{l}\text { 'The treatment has made me more aware of my disability and has provided } \\
\text { me with ideas of how to overcome tasks that have been difficult.' Found all } \\
\text { the strategies helpful and still adopts them, but activities did not stretch } \\
\text { him enough. } \\
\text { 'I need to scan using my eyes when completing a task.' } \\
\text { 'Now I make an effort when talking to my wife when she is sitting on my } \\
\text { right side.' } \\
\text { Liked: Reading, being timed to find keys, scanning in the workshop } \\
\text { Not liked: scanning the room, participant felt this was a memory test and } \\
\text { his memory was too good. The search tasks were not challenging enough. }\end{array}$ & 6 \\
\hline B & $\begin{array}{l}\text { 'I pay attention more to the left side, although I still have visual problems.' } \\
\text { Liked: Scanning exercises for eyes; Not liked: None }\end{array}$ & 5 \\
\hline C & $\begin{array}{l}\text { 'A great help getting me to understand the limitations that I did not realise I } \\
\text { had. I thought when I was coming out of hospital I was fine, thought I could } \\
\text { do everyday things. It made me realise how badly it has affected me.' } \\
\text { [Giving an example regarding safety in the kitchen, when using a knife]: 'I } \\
\text { am turning my head to look at the tomato to get the right thickness. I find it } \\
\text { easier to hold the tomato, missing my finger and thumb. It has made me } \\
\text { safer.' } \\
\text { No likes or dislikes reported in responses }\end{array}$ & 8 \\
\hline D & $\begin{array}{l}\text { 'Helped to find objects, previously I couldn't find objects even if they were } \\
\text { right in front of me.' 'I can get my own meals now.' } \\
\text { Liked: Out walking in the community, finding objects; Not liked: None }\end{array}$ & 7 \\
\hline $\mathbf{F}$ & $\begin{array}{l}\text { 'I can look for things and turn my head more. My head is more central. I can } \\
\text { do cleaning. I can look out of the window and see my family arriving; watch } \\
\text { TV and Olympic sports, world affairs. I still struggle with the phone.' } \\
\text { Liked: Finding the paper bits is helpful. Picking up paper bits from floor with } \\
\text { the hoover, picked out my clothes in the morning, put on my cream and a } \\
\text { bit of perfume. Everything was helpful. }\end{array}$ & 10 \\
\hline
\end{tabular}




\begin{tabular}{|c|l|c|}
\hline & Not liked: none & \\
\hline $\mathbf{G}$ & $\begin{array}{l}\text { I' have been put back on the map again. I was lifted, given another chance; I } \\
\text { feel as if I've improved since the OT has been going on' } \\
\text { Liked: All helpful; Not liked: None }\end{array}$ & $\begin{array}{c}\text { No } \\
\text { rating } \\
\text { given }\end{array}$ \\
\hline H & $\begin{array}{l}\text { 'I am far more aware of scanning, and it has made a difference for me doing } \\
\text { everyday tasks. Easier to find things now. I have improved considerably. ' } \\
\text { Liked: She used a lot of pressure at looking at her - eye contact, putting } \\
\text { things out of my sight on my side. I liked doing the cutlery drawer, putting } \\
\text { things back and turning head to look for items } \\
\text { Not liked: When I wanted to do it one way and S wanted to do it another } \\
\text { way - the way I do things is different. I understand why it was like this but } \\
\text { having to learn new ways of doing things is difficult. }\end{array}$ & 8 \\
\hline I & $\begin{array}{l}\text { 'I feel more confident each time I go out.'; 'I have not mastered the } \\
\text { computer keyboard' } \\
\text { 'I cannot make as much progress in the kitchen as I would like' } \\
\text { Liked: 'Going to the shop was fun; Not liked: None }\end{array}$ & 6 \\
\hline
\end{tabular}


Table 4. VFQ25 scores

\begin{tabular}{lcccccccc}
\hline Participant * & A & C & D & E & F & G & H & I \\
\hline $\begin{array}{l}\text { Composite } \\
\text { score }\end{array}$ & & & & & & & & \\
\hline $\begin{array}{l}\text { Before training } \\
\text { After training }\end{array}$ & 82.7 & 56.0 & 20.3 & 59.0 & 45.1 & 90.0 & 60.3 & 45.6 \\
\hline $\begin{array}{l}\text { Change in } \\
\text { composite } \\
\text { score }\end{array}$ & $\mathbf{8 . 9}$ & $\mathbf{3 1 . 8}$ & $\mathbf{4 5 . 3}$ & $\mathbf{2 9 . 8}$ & $\mathbf{2 2 . 2}$ & $\mathbf{3 . 6}$ & $\mathbf{1 0 . 0}$ & $\mathbf{6 . 6}$ \\
\hline
\end{tabular}

Change scores in each domain

\begin{tabular}{|c|c|c|c|c|c|c|c|c|}
\hline \multicolumn{9}{|l|}{ Visual function } \\
\hline Gen vision & 0 & 0 & 20 & 20 & 20 & 0 & 40 & 20 \\
\hline Near & -8 & 25 & 17 & 25 & 25 & 0 & 25 & 8 \\
\hline Distance & 0 & -8 & 46 & 50 & 0 & $* * *$ & -9 & 0 \\
\hline Peripheral & 50 & 50 & 25 & 25 & $* * *$ & $* * *$ & 25 & 0 \\
\hline Colour ** & 0 & 50 & 75 & 0 & $* * *$ & $* * *$ & 0 & 0 \\
\hline \multicolumn{9}{|c|}{ Socio-emotional function } \\
\hline Social function & 0 & 50 & 50 & 25 & 0 & 0 & 0 & 25 \\
\hline Role & 25 & 100 & 37 & 75 & 37 & 25 & 12 & 63 \\
\hline Dependency & 0 & 25 & 75 & 17 & 33 & 0 & -9 & -50 \\
\hline Mental health & 12 & -6 & 62 & 31 & 37 & 0 & 6 & -19 \\
\hline
\end{tabular}

VFQ 25 questionnaire items are scored so that a high score represents better functioning * Participant B did not complete VFQ25 post intervention, his composite score before intervention was 83.6. ** Colour is a question that asks participants to rate how much difficulty they have picking out and matching clothes because of eyesight. Participants in this study may have difficulty picking out clothing due to search difficulties rather than due to colour vision. ${ }^{* * *}$ Participants responded to questions about activities in distance, peripheral and colour with the option: Stopped doing this for other reasons or not 
interested in doing this; for example, the peripheral vision item is a question that asks 'Because of your eyesight, how much difficulty do you have noticing objects off to the side while you are walking along? Participants $F \&$ G could not answer this question since they are unable to walk.

\section{Figure legends}

\section{Figure 1. Room search and Head worn camera (inset)}

A Go-Pro digital head worn video camera secured with an elastic strap (inset). The position of the camera was aligned using a laser pointer to ensure the camera was facing straight ahead when the participant was looking at an object directly in front of them.

The object was hidden in eight sections of the room: left upper, left lower, central left upper, central left lower, central right upper, central right lower, right upper, right lower. A grid drawn later by the tester was used for analysis of the searches.

\section{Figure 2 Participants' room search performances before and after the intervention}

Individual participants are labelled A-I on the $\mathrm{x}$ axis of each chart. Dark bars represent scores before intervention, light open bars after intervention. The error bars in Graphs A and B represent mean $95 \%$ confidence intervals $(\mathrm{Cl})$ for the individual's before and after intervention conditions. Each of these Cls are based on an average of 162 head-directions (range: 52-266) in Graph A. In Graph B 'early search' was defined as the first five head directions in each search and these data are again plotted with mean $95 \%$ Cis. These Cls are based on an average of 62 head-directions (range: 46-76). For Graphs C and D median search times plotted. The bars on these graphs represent the inter quartile range (IQR) in each case. Note that these medians and IQRs are based on only 8 observations each and that the trials were timed-out at 120 seconds. 